\title{
Caspase-9 Activation Revealed by Semaphorin 7A Cleavage Is Independent of Apoptosis in the Aged Olfactory Bulb
}

\author{
Shizue Ohsawa, ${ }^{1}$ Shun Hamada, ${ }^{3}$ Hiroaki Asou, ${ }^{4}$ Keiuke Kuida, ${ }^{5}$ Yasuo Uchiyama, ${ }^{6}$ Hiroki Yoshida, ${ }^{7}$ \\ and Masayuki Miura ${ }^{1,2}$ \\ ${ }^{1}$ Department of Genetics, Graduate School of Pharmaceutical Sciences, University of Tokyo, and 2CREST, JST, Bunkyo-ku, Tokyo 113-0033, Japan, \\ ${ }^{3}$ Laboratory for Cellular and Molecular Neuroscience, Department of Nutrition and Health Science, Faculty of Human Environmental Science, Fukuoka \\ Women's University, Higashi-ku, Fukuoka 813-8529, Japan, ${ }^{4}$ Department of Neuro-Glia Cell Biology, Tokyo Metropolitan Institute of Gerontology, \\ Itabashi, Tokyo 173-0015, Japan, ${ }^{5}$ Department of Biology, Vertex Pharmaceuticals, Cambridge, Massachusetts 02139, ${ }^{6}$ Department of Cell Biology and \\ Neuroscience, Juntendo University Graduate School of Medicine, Tokyo 113-8421, Japan, and ${ }^{7}$ Department of Biomolecular Sciences, Faculty of Medicine, \\ Saga University, Saga 849-8501, Japan
}

Caspases are essential in multicellular organisms for inducing cell death during normal development and in the immune system. However, caspases can also trigger the degenerative process under certain conditions such as pathophysiological conditions and aging. Here, we identified Semaphorin 7A (Sema7A) as a novel substrate for caspase- 9 that can be used to monitor caspase- 9 activity in mice, and found nonapoptotic caspase-9 activation in the aged olfactory bulb (OB). Immunostaining of the $\mathrm{OB}$ for the caspase-9-cleaved form of Sema7A revealed abundant caspase-9-activated cells in 2-year-old (aged) but not in 2-month-old (young) mice. In fact, various regions of the aged brain, including the $\mathrm{OB}$, exhibited an increased level of caspase- 9 activity. However, the number of dying cells in the aged $0 \mathrm{~B}$ was, intriguingly, much lower $(<20 \%)$ than in the $\mathrm{OB}$ of young mice. Furthermore, we found that the lower number dying cells in the aged $\mathrm{OB}$ was accompanied by a decreased expression of procaspase-3. These results suggest a survival strategy for aged OB neurons, which can no longer regenerate, in which the central apoptotic machinery downstream of caspase- 9 is inactivated.

\section{Introduction}

Programmed cell death is the essential process for eliminating superfluous or harmful cells in multicellular organisms (Jacobson et al., 1997). The central players in apoptosis are a family of cysteine proteases called caspases (Miura and Yuan, 1996; Kumar, 2007). Caspases are synthesized as precursor proteins, requiring specific processing for their activation. The processing of a caspase is elicited by its upstream caspase; thus, caspases comprise an activating protease cascade. Caspases are therefore divided into two classes: initiator caspases and effector caspases. The initiator caspases include caspases-2, -8, -9, -10, -11 in mammals and Dronc and Dredd in Drosophila, and the effector caspases include caspases-3, -6 , and -7 in mammals and Drice and Dcp 1 in Drosophila. The initiator caspase, caspase-9, is a crucial member of the family, essential for most cell deaths during normal

\footnotetext{
Received Oct. 4, 2008; revised May 24, 2009; accepted Aug. 4, 2009.

This work was supported in part by grants from the Japanese Ministry of Education, Science, Sports, Culture, and Technology and a RIKEN Bioarchitect Research Grant (to M.M.) and by Research Fellowships of the Japan Society for the Promotion of Science for Young Scientists (to S.O). We thank T. Igaki (Kobe University) for helpful discussions and encouragement and N. Oikawa (University of Tokyo) for technical assistance. We also thank T. Seki (Tohoku University) for the mouse monoclonal anti-PSA-NCAM antibody, A. Yamada (Kurume University) for the Sema7A-pCMVSPORT, T. Tsuruo (University of Tokyo) and T. Mashima (Cancer Chemotherapy Center) for the pcDNA3-caspase-9 DN, and R. Takahashi (Kyoto University) for the pcDNA3-reverse caspase-3. We further thank Y. Yamaguchi (University of Tokyo) and M. Koike (Juntendo University) for preparing caspase-3 knock-out mice.

Correspondence should be addressed to Masayuki Miura, Department of Genetics, Graduate School of Pharmaceutical Sciences, University of Tokyo, 7-3-1 Hongo, Bunkyo-ku, Tokyo 113-0033, Japan. E-mail: miura@mol.f.u-tokyo.ac.jp.

D01:10.1523/JNEUROSCI.4780-08.2009

Copyright $\odot 2009$ Society for Neuroscience $\quad 0270-6474 / 09 / 2911385-08 \$ 15.00 / 0$
}

development. However, recent studies in Drosophila suggest that the fly ortholog of caspase-9, Dronc, not only induces cell death but also regulates nonapoptotic processes, such as dendritic pruning of larval neurons, spermatid individualization, border cell migration, neural precursor development, and compensatory proliferation (Kumar, 2004; Kuranaga and Miura, 2007). One mechanism by which caspases cause such nonapoptotic effects appears to be through the regulation of their activation threshold: in the same cell type, a low level of caspase activity or a localized activation of caspases leads to a nonapoptotic effect, but their strong activation results in apoptosis (Kuo et al., 2006; Kuranaga et al., 2006; Williams et al., 2006). Thus, spatiotemporal regulation of the level of caspase activity may be crucial for multicellular organisms to maintain homeostasis.

Although caspase-dependent programmed cell death plays an essential role during normal development and tissue homeostasis, it can potentially induce undesirable cell deaths under certain conditions, such as pathological conditions and aging. Such unwanted cell deaths can be closely linked to neurodegeneration, stroke, traumatic brain injury, and aging. To avoid causing unwanted cell death, the activity of the caspase cascade must be tightly regulated. Activation of the caspase-9-dependent cascade is controlled by the mitochondrial release of cytochrome $c$. However, the molecular mechanism by which this cascade is regulated during normal development and aging is poorly understood. One reason for the lack of information is that caspase- 9 activation in tissues is hard to detect due to its low enzymatic activity, even in dying cells. Here, we found that Sema7A is a unique substrate of 

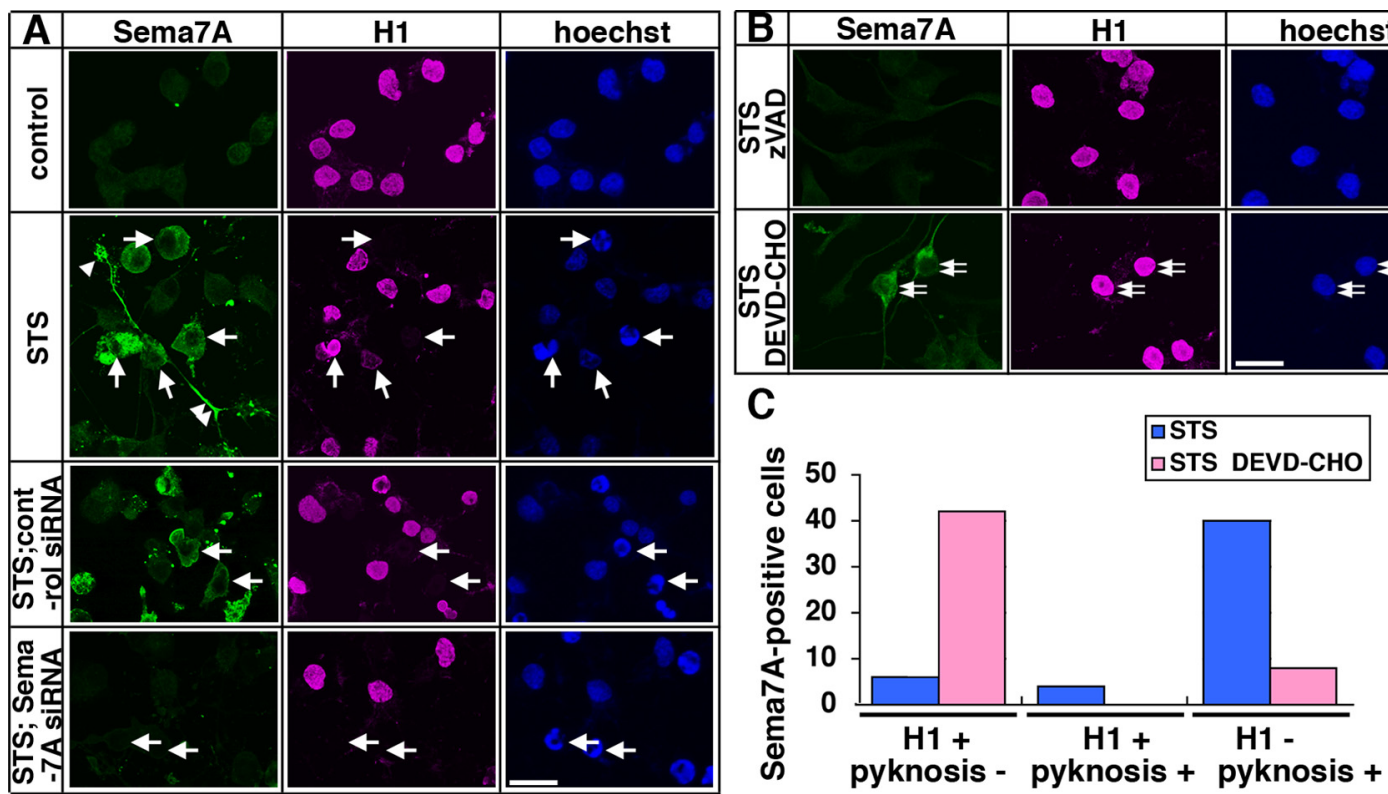

Figure 1. Caspase-dependent appearance of Sema7A immunoreactivity in cultured cells. A-C, Neuro-2a cells were treated with $250 \mathrm{~nm} \mathrm{STS} \mathrm{for} 4 \mathrm{~h}$. To examine whether the anti-Sema7A antibody specifically immunolabeled Sema7A, Neuro-2a cells were transfected with siRNA for Sema7A and incubated for $72 \mathrm{~h}$. ZVAD-fmk (100 $\mu \mathrm{M})$ or AC-DEVD-CHO (100 $\mu \mathrm{M})$ was added to the cells $2 \mathrm{~h}$ before the treatment with STS $(\boldsymbol{B})$. The cells were then immunostained for Sema7A (green) and H1 (AE-4 monoclonal antibody). Arrows in $\boldsymbol{A}$ show H1-negative dying cells. The nuclei were stained with Hoechst 33342. Arrowheads in $\boldsymbol{A}$ show the strong immunoreactivity of the Sema7A antibody to the neurites of an apoptotic Neuro-2a cell. Double arrows in $\boldsymbol{B}$ show Sema7A-and histone H1-positive cells. Fifty Sema7A-positive cells were classified as to whether they were undergoing caspase-dependent cell death based on their staining patterns with the AE-4 anti-H1 antibody and Hoechst 33342 in (C). Scale bars, $20 \mu \mathrm{m}$.

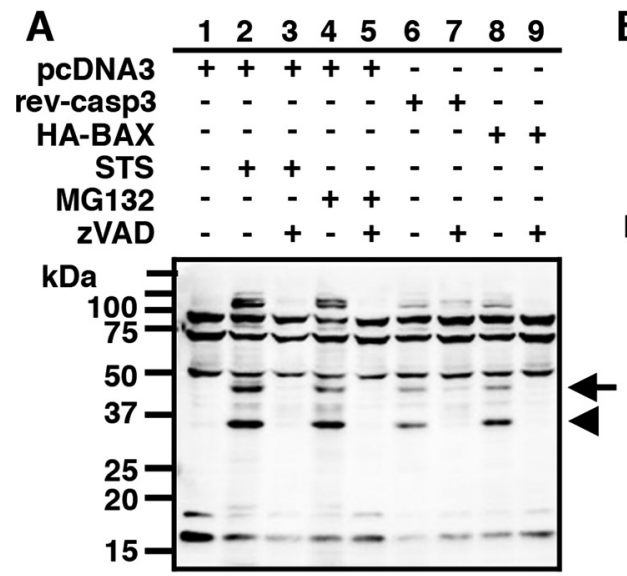

Sema7A

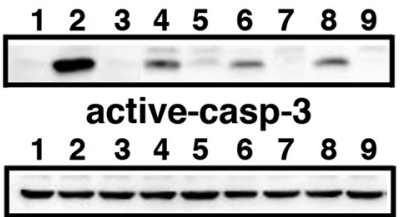

$\beta$-tubulin
B
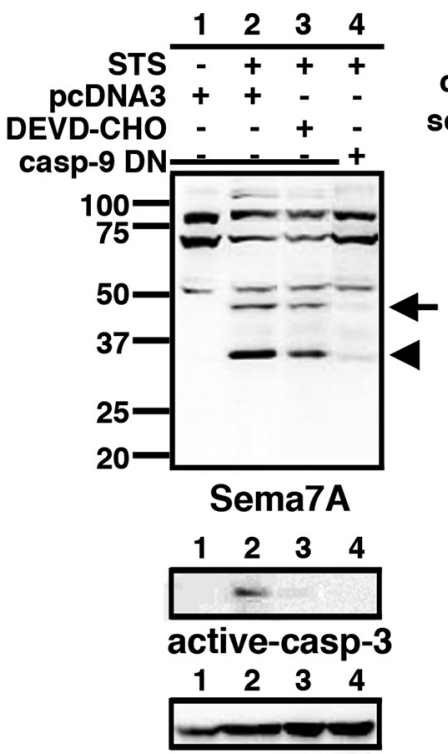

$\beta$-tubulin

C
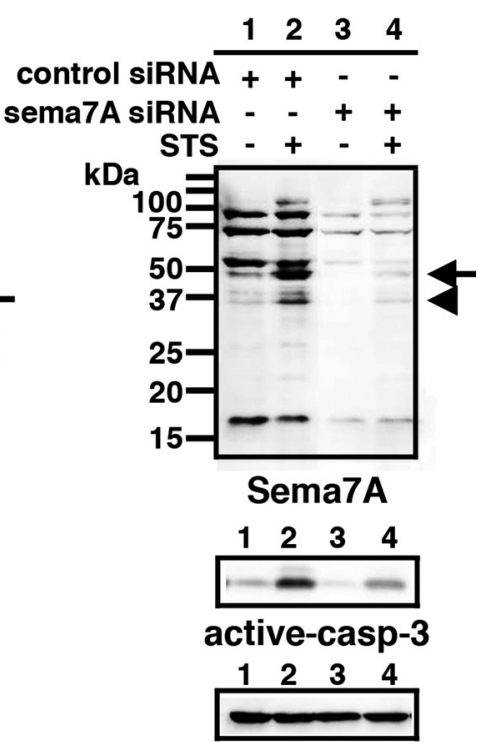

$\beta$-tubulin

Figure 2. Sema7A was cleaved in a caspase-dependent manner. Whole-cell extracts were analyzed by immunoblotting using anti-Sema7A, anti-active-caspase-3, and anti- $\beta$-tubulin antibod-

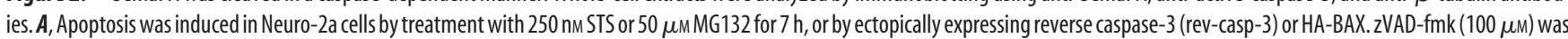
added to inhibit caspase activation. $\boldsymbol{B}$, Neuro-2a cells were transfected with either pcDNA3 or caspase-9 DN-pcDNA3 and then exposed to STS for $7 \mathrm{~h}$. DEVD-CHO (100 $\mu \mathrm{m}$ ) was added to the cells $2 \mathrm{~h}$ before STS treatment. $C$, Neuro-2a cells were transfected with the indicated siRNA and incubated for $72 \mathrm{~h}$, followed by exposure to STS for $5 \mathrm{~h}$. Arrows and arrowheads show the caspase-dependent cleaved fragments of Sema7A.

caspase-9. Immunostaining by a commercially available affinitypurified Sema7A antibody (hereafter, we refer to it as the antiSema7A antibody) can be a sensitive detection method for caspase-9 activity in vivo. Using this novel method, we found nonapoptotic caspase-9 activation in the aged olfactory bulb $(\mathrm{OB})$ of mice. We also found that caspase- 3 expression was decreased in the aged OB compared with the young OB. The downregulation of caspase- 3 expression could be a survival strategy by 
A

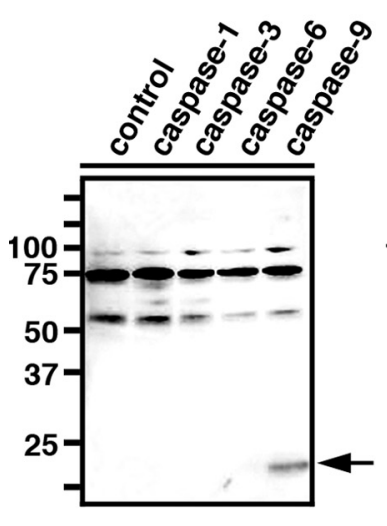

Sema7A
B

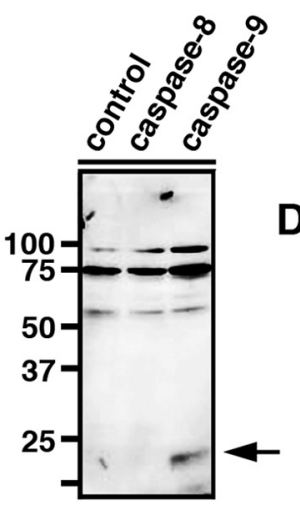

Sema7A
C signal

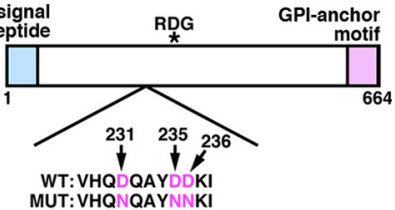

D

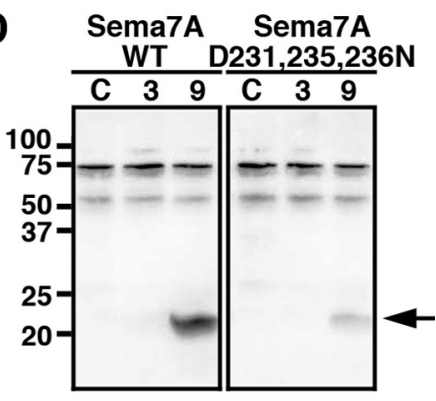

Sema7A

Figure 3. In vitro cleavage analysis of Sema7A. $\boldsymbol{A}, \boldsymbol{B}$, Sema7A synthesized in vitro was cleaved by $1 \mathrm{U}$ of purified activated caspase- $1,-3,-6,-8$, or -9 in a $2 \mathrm{~h}$ incubation. As a control, DMSO was used instead of purified activated caspases. The reaction mixture was then subjected to immunoblot analysis using the anti-Sema7A antibody. C, Schematic of mouse Sema7A. The signal sequence and GPI anchor motif are indicated by a pink and a blue box, respectively. The integrin-binding motif, RGD, is indicated by an asterisk. The possible cleavage site for caspase-9 was within the VHQD(231)QAYD(235)D(236) motif in Sema7A. D, Cleavage assay for wild-type (WT) and the indicated mutant Sema7A using purified activated caspase-3 (3) or caspase-9 (9). The mutation of Asp (D) $231,235,236$ to Asn (N) in Sema7A strongly inhibited its cleavage by caspase-9. Arrows show the cleaved fragment of Sema7A. C, DMSO.

which aged olfactory bulb neurons avoid caspase-9-triggered cell death signaling. It could also be a strategy for exerting nonapoptotic functions through the cleavage of axonal regulatory proteins, including Sema7A.

\section{Materials and Methods}

Mice. C57BL/6 mice were purchased from CLEA Japan. Twenty-fourmonth-old C57BL/6S mice were obtained from colonies maintained by the Tokyo Metropolitan Institute of Gerontology. apaf-1(+/-) and apaf-1(-I-) mice were generated by interbreeding heterozygotes (Yoshida et al., 1998). caspase-3 heterozygous (+/-) mice backcrossed onto a C57BL/6 background for at least 10 generations were used to generate caspase-3 (-/-) mice (Kuida et al., 1996; Koike et al., 2008). Methods for inducing proliferative cell death by cytosine arabinoside (Ara C) in embryonic mice have been described previously (Ohsawa et al., 2008a).

Constructs. The vector encoding mouse Sema7A (Sema7A-pCMVSPORT) was kindly provided by A. Yamada (Mine et al., 2000). Sema7A cDNA was subcloned into the EcoRI/HindIII site of pBluescript SK (+/-). The Sema7A mutants D231, 235, 236N; E181, 184G/D183G; and D245, 248G, were constructed by PCR mutagenesis using Sema7A-pBluescript as a template.

Immunohistochemistry. Mice were anesthetized deeply by pentobarbital and perfused through the ascending aorta with saline followed by $4 \%$ paraformaldehyde in $0.1 \mathrm{M} \mathrm{PB}, \mathrm{pH} 7.3$, for $15 \mathrm{~min}$. The brains were removed and immersed in the same fixative for $2-3 \mathrm{~h}$ at $4^{\circ} \mathrm{C}$. The tissues were immersed in $25 \%$ sucrose in $0.1 \mathrm{M} \mathrm{PB}$ at $4^{\circ} \mathrm{C}$ overnight. Tissues were then frozen quickly by hexane cooled with dry ice and $5 \mu \mathrm{m}$ sections were cut on a cryostat (Leica CM3050) and thaw-mounted on slides. We also used fresh frozen sections fixed by methanol for immunohistochemistry. Mice were anesthetized deeply and decapitated. The brains were removed rapidly and immersed in embedding material (OCT compound; Miles). The brains were quickly frozen by hexane cooled with dry ice. The fresh-frozen sections were then cut on a cryostat and thaw-mounted on slides. Before immunohistochemical procedures, sections were fixed by cold methanol for $15 \mathrm{~min}$. These two methods gave essentially the same results.

The staining method used for immunohistochemistry has been described previously (Ohsawa et al., 2005). The following antibodies were used at the indicated dilutions: rabbit monoclonal anti-active caspase-3 C92-605 (BD; 1:1000), rabbit polyclonal anti-Sema7A (Abcam; $1: 100)$, mouse monoclonal anti-PSA-NCAM (kindly provided by T. Seki; 1:500) (Seki and Arai, 1991), and rabbit polyclonal anti-cleaved caspase-9 (Asp353) (Cell Signaling Technologies; 1:100). The TUNEL assay (In Situ Cell Death Detection kit; Roche) was performed according to the manufacturer's instructions.

Cells, transfection, immunostaining, preparation of cell lysates, and immunoblotting. Neuro-2a cells were cultured in DMEM containing $10 \%$ fetal bovine serum and $2 \mathrm{~mm}$ L-glutamine. Cells were transfected using Lipofectamine 2000 reagent (Invitrogen BRL) following the manufacturer's instructions. The methods used for immunostaining and immunoblotting have been described previously (Ohsawa et al., 2008a). The following antibodies were used at the indicated dilutions: rabbit monoclonal antiactive caspase-3 C92-605 (BD; 1:1000), rabbit polyclonal Sema7A (Abcam; 1:500), mouse monoclonal caspase-9 (MBL; 1:1000), mouse monoclonal caspase-3 antibody C92-605 (BD; 1:1000), mouse monoclonal cleaved PARP 7C9 (Cell Signaling Technologies; 1:1000), mouse monoclonal anti-H1 clone AE-4 (Upstate; $1: 200)$, and mouse monoclonal anti- $\beta$ tubulin (Millipore Bioscience Research Reagents; 1:1000).

Caspase activity assays. Cytoplasmic extracts of young and aged brains were prepared for caspase activity assays as described previously (Kanuka et al., 1999), with several modifications. Mouse tissues were dissected, immediately frozen in liquid nitrogen, and stored at $-80^{\circ} \mathrm{C}$. Suspension buffer (50 mм Tris-HCl, pH 7.5, 1 mм EDTA, 10 mм EGTA, and $10 \mu \mathrm{M}$ digitonin) was added to tissues, then mixtures were voltexed and incubated for $10 \mathrm{~min}$ at $37^{\circ} \mathrm{C}$, and then cell lysates were cleared by centrifugation. Cell lysates containing $4 \mu \mathrm{g}$ of protein were mixed with an equal volume of assay buffer (20 mM HEPES, pH 7.4, $100 \mathrm{~mm} \mathrm{NaCl}, 0.05 \%$ $\mathrm{NP} 40$, and $5 \mathrm{~mm} \mathrm{MgCl}_{2}$ ) and preincubated at $37^{\circ} \mathrm{C}$ for $30 \mathrm{~min}$. Assay buffer $(1 \mathrm{ml})$ containing $10 \mu \mathrm{M}$ enzyme substrate Ac-YVAD-MCA, AcDEVD-MCA, Ac-IETD-MCA, or Ac-LEHD-MCA (Peptide Institute, Osaka) was added to the lysate, and the mixture was incubated at $37^{\circ} \mathrm{C}$ for $30 \mathrm{~min}$. The level of released 7-amino-4-methylcoumarin was measured using a spectrofluorometer (Biolumin 960, Molecular Dynamics) with excitation at $380 \mathrm{~nm}$ and emission at $460 \mathrm{~nm}$. Activity was expressed in picomoles of 7-amino-4-methylcoumarin generated. The data were collected from three independent experiments and are presented as the mean $\pm \mathrm{SD}$.

RNA interference in Neuro-2a cells. Neuro-2a cells were transfected with the siRNA for Sema7A (Invitrogen; target sequence ACUUGUGUACAGUUCACUCUCGCCC or GGGCGAGAGUGAACUGUACACAAGU) and a control siRNA [Qiagen; target sequence AATTCTCCGAACGTGTCACGT or the siRNA for LacZ generated by a BLOCK-iT RNAi TOPO Transcription Kit (Invitrogen)] by use of the Lipofectamine 2000 reagent (Invitrogen) following the manufacturer's instructions. Seventy-two hours after the transfection, the cells were exposed to $250 \mathrm{~nm}$ staurosporine (STS), followed by immunostaining or immunoblotting as described above.

In vitro cleavage of Sema7A. The in vitro cleavage assay was performed as described previously (Takemoto et al., 2003). Sema7A protein was prepared by in vitro transcription and translation using a TNT-coupled reticulocyte lysate system (Promega). Wild-type or mutant Sema7A (2 $\mu \mathrm{l})$ was incubated at $37^{\circ} \mathrm{C}$ in $20 \mu \mathrm{l}$ of reaction mixture with $1 \mathrm{U}$ purified active caspase- $1,-3,-6,-8$, or -9 (MBL) for 2 or $4 \mathrm{~h}$. The buffer for the reaction mixture contained $20 \mathrm{~mm}$ HEPES, $\mathrm{pH} 7.5,10 \mathrm{~mm} \mathrm{KCl,} 1.5 \mathrm{~mm}$ $\mathrm{MgCl}_{2}, 1 \mathrm{~mm}$ EDTA, $1 \mathrm{~mm}$ EGTA, $1 \mathrm{~mm}$ DTT, $0.1 \mathrm{~mm}$ PMSF, $2 \mu \mathrm{g} / \mathrm{ml}$ aprotinin, and $5 \mu \mathrm{g} / \mathrm{ml}$ pepstatin $\mathrm{A}$. 


\section{Results}

An antibody against Sema7A

preferentially immunolabeled

caspase-dependent apoptotic cells

Sema7A is a membrane-anchored member of the semaphorin family of guidance proteins, known for its effects on axonal growth in the nervous system and its diverse functions in the immune system (Suzuki et al., 2007). A deficiency of Sema7A in mice impairs the formation of the lateral olfactory tract, which is a caudally extending fiber bundle from mitral cells in the OB (Pasterkamp et al., 2003). The overexpression of Sema7A enhances the neurite outgrowth of cultured neural cells, including olfactory sensory neurons (OSNs), cortical neurons, and thalamic neurons (Pasterkamp et al., 2007; Maruyama et al., 2008). Intriguingly, we found that a rabbit polyclonal antibody against amino acid residues 1-100 of mouse Sema7A strongly immunolabeled olfactory sensory axons projecting to the anterior-medial and posterior-ventral regions of the olfactory bulb, a region where caspase-3 is strongly activated (supplemental Fig. $2 C$, available at www.jneurosci.org as supplemental material; unpublished data). apaf-1 or caspase-9 deficiency abolished the immunoreactivity of both anti-active-caspase- 3 and antiSema7A antibodies in the olfactory sensory axons. Thus, there appeared to be a relationship between Sema7A and caspase activity in neurons.

To analyze this relationship in detail, we used the mouse neuroblastoma cell line Neuro-2a (Fig. 1). Immunofluorescent labeling of Neuro-2a cells revealed that the anti-Sema7A antibody failed to recognize healthy cells, even though these cells expressed Sema7A (Fig. 1A, 2A). In contrast, this antibody labeled STS-treated cells (hereafter, "Sema7A-positive" cells) that were undergoing caspase-dependent cell death, which was characterized by the loss of AE- 4 anti-H1 immunoreactivity (Ohsawa et al., 2008a) (Fig. 1A). Treatment of the Neuro-2a cells with the pan-caspase inhibitor zVAD-fmk suppressed not only the STS-induced cell death but also the immunoreactivity of these cells with the anti-Sema7A antibody (Fig. $1 B$ ). In contrast, an inhibitor of caspase-3-like proteases, Ac-DEVD-CHO, failed to suppress the labeling for Sema7A in STS-treated Neuro-2a cells, suggesting that a non-DEVDase activity is involved in the Sema7A immunoreactivity (Fig. $1 B, C$ ). Furthermore, the siRNAmediated knock-down of Sema7A in Neuro-2a cells abolished their immunoreactivity with the anti-Sema7A antibody, indicating that this antibody indeed recognized Sema7A (Fig. 1A). These data suggest that the anti-Sema7A antibody recognizes Sema7A specifically in cells undergoing caspase-dependent cell death.

Caspase-9-dependent cleavage of Sema7A during apoptosis The Sema7A protein contains a glycosylphosphatidylinositol (GPI)-anchored motif and several putative N-linked glycosylation sites. In Western blot analysis, the anti-Sema7A antibody detects three types of Sema7A (of $\sim 100,75$, and $50 \mathrm{kDa}$ ) in healthy Neuro-2a cells, all of which are abrogated by preincubation of the antibody with the immunizing peptide, according to the information provided by Abcam. We observed the same three Sema7A bands, which were abolished by the siRNA knockdown of Sema7A (Fig. 2C).

To investigate the molecular nature of the Sema7A in dying cells, Neuro-2a cells were treated with STS or MG132 (Fig. 2A). Endogenous Sema7A was cleaved in response to these apoptotic stimuli (Fig. 2, arrow and arrowhead). The same cleavage pattern was observed when autocatalytic reverse caspase-3 (Suzuki et al., 2001) or proapoptotic HA-BAX was overexpressed in Neuro-2a cells (Fig. 2A). Since activated caspase-3 cleaves caspase 9 in a positive-feedback loop (Srinivasula et al., 1998; Slee et al., 1999; Srinivasula et al., 2001), the expression of reverse caspase-3 would be expected to activate initiator caspase-9. The pancaspase inhibitor zVAD, as well as caspase-9 DN, inhibited the processing of Sema7A (Fig. 2 B). Furthermore, pretreatment with a caspase- 3 inhibitor, Ac-DEVD-CHO, had only subtle effects on the cleavage of Sema7A (Fig. 2 B), suggesting that this antibody specifically detects the caspase-9-cleaved form of Sema7A. Furthermore, Western blot analysis of Sema7A-knock-down cells 

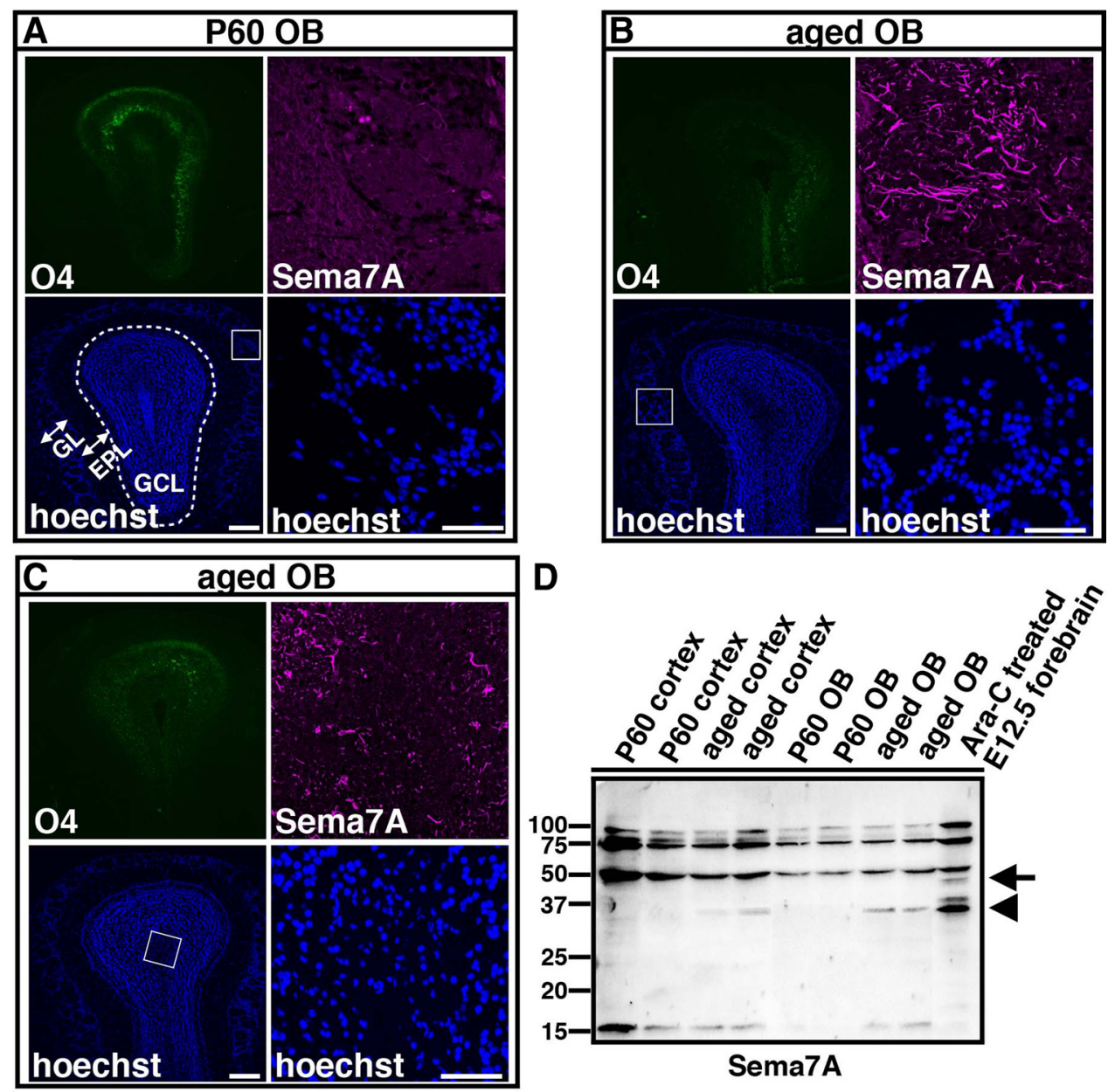

Figure 5. Cleavage of Sema7A in the aged OB. A-C, Coronal sections (5 $\mu \mathrm{m}$ thick) of postnatal day 60 (P60) (A) and 24-month-old (aged) (B, C) 0B were stained with anti-04 (a marker for oligodendrocytes; green) and anti-Sema7A (magenta) antibodies. Nuclei were stained with Hoechst 33342 (blue). EPL, External plexiform layer; GL, glomerular layer. Scale bar, 50 $\mu$ m. D, Whole-cell extracts $(60 \mu \mathrm{g})$ of the indicated mouse tissues were analyzed by immunoblotting using the anti-Sema7A antibody.

confirmed that the STS-induced fragments were indeed derived from Sema7A (Fig. 2C). These data suggest that Sema7A is cleaved by active caspase- 9 , but not by active caspase- 3 , in dying cells.

\section{Sema7A is a direct substrate of caspase- 9}

To examine whether caspases could directly cleave Sema7A, recombinant Sema7A protein was digested with purified active-caspase-1, $-3,-6,-8$, or -9 in vitro. Incubation of Sema7A protein with caspase-9 resulted in the appearance of a cleavage fragment migrating at 24 $\mathrm{kDa}$ (Fig. $3 A, B)$. The different size of this cleavage fragment relative to those obtained from cultured Neuro-2a cells might be because of the lack of post-translational modification in the in vitro-translated Sema7A. We mapped the site cleaved by caspase- 9 by constructing mutant Sema7A proteins for putative caspase-cleaved sites (Thornberry et al., 1997). Mutations of Asp231, 235, and 236 to Asn $(\mathrm{VHQDQAYDD} \rightarrow \mathrm{VHQNQAYNN}$ ) in Sema7A blocked the cleavage by caspase-9 (Fig. 3C). A single mutation of Asp231 to Gly in Sema7A also largely blocked its cleavage by caspase- 9 (supplemental Fig. $1 A$, available at www.jneurosci.org as supplemental material). In contrast, other putative cleavage site mutations, including E181D, E184G, D183G, D245G, and D248G, failed to block the cleavage by caspase-9 (supplemental Fig. $1 B$, available at www.jneurosci.org as supplemental material). These data suggest that the VHQDQAYDD motif in Sema7A, which is evolutionarily conserved among human, mouse, and rat, is the likely cleavage site for caspase-9.
Apaf-1-dependent cleavage of Sema7A and the appearance of Sema7A-positive cells among genotoxin-induced dying cells in the mouse embryo

To examine whether Sema7A undergoes caspase-dependent changes during apoptosis in vivo, we compared the staining patterns of the Sema7A antibody in wild-type and apaf-1-mutant mice, which are deficient for caspase activation (Yoshida et al., 1998). Apaf- 1 is essential for the activation of caspase- 9 and is required for the induction of apoptosis by the DNA-damaging reagent Ara C) in neural precursor cells of the embryonic cortex (D'Sa et al., 2003). We observed a number of dying cells with condensed nuclei in the ventricular zone of Ara C-treated apaf-1 $(-/+)$ embryos (Fig. 4A). Consistent with our in vitro data, these cells were specifically stained with the Sema7A antibody. In contrast, apaf-1-deficient homozygous embryos were resistant to the Ara C-induced cell death, and were not stained with the Sema7A antibody, with the exception of few pyknotic cells (Ohsawa et al., 2008a), indicating that the anti-Sema7A antibody specifically immunolabeled Apaf-1-dependent apoptotic cells (Fig. 4A). Furthermore, immunoblotting confirmed the results of this immunofluorescence analysis (Fig. 4B,C). These data suggest that Sema7A is cleaved in a caspase-dependent manner in vivo and can be used to detect caspase-dependent apoptosis in mice. 


\section{Positive-feedback activation of caspase- 9 by caspase- 3 in Ara C-treated embryonic brain}

Caspase-3 is known to function downstream of caspase-9. Caspase- 9 activation was observed in $\gamma$-irradiated caspase- 3 $(-/-)$ neural precursor cells in vitro (D'Sa et al., 2003). On the other hand, previous studies have also suggested that activated caspase- 3 is required for the processing and complete activation of caspase-9 (Srinivasula et al., 1998, 2001; Slee et al., 1999; Fujita et al., 2001). However, little is known about the significance of caspase- 3 activity in caspase- 9 activation in vivo. We thus examined whether caspase- 9 is activated and cleaves its substrates in response to DNA damage in the ventricular zone of caspase-3 (-/-) embryos. Caspase-3-deficient homozygous embryos were resistant to Ara C-induced cell death in the ventricular zone of the embryonic cortex, which is consistent with the previous report (D'Sa-Eipper et al., 2001). Intriguingly, we found that almost all cells were not stained with a commercially available anti-cleaved mouse caspase-9 (Asp353) and the Sema7A antibody, with the exception of few pyknotic cells (supplemental Fig. 2, available at www. jneurosci.org as supplemental material), suggesting that caspase-3 activity induced caspase- 9 activation and following cleavage of Sema7A in a positive-feedback loop in Ara C-treated embryonic brain. Furthermore, we also examined whether caspase- 3 activity is required for the cleavage of Sema7A in the developing olfactory system. Anti-active-caspase- 3 and the Sema7A antibodies immunolabeled the olfactory sensory axons projecting to the anterior-medial and posterior-ventral regions of the olfactory nerve layer in caspase-3 (+/-) OB (supplemental Fig. 2C, available at www. jneurosci.org as supplemental material; unpublished data). In contrast, caspase-3 deficiency abolished the immunoreactivity of not only anti-active-caspase- 3 but also anti-Sema7A antibodies in the olfactory sensory axons (supplemental Fig. 2C, available at www. jneurosci.org as supplemental material). These data suggest that the feedback activation of caspase- 9 by caspase- 3 also functions in the normal development of the olfactory system.

\section{Caspase-9 activation in the aged $\mathrm{OB}$}

We next applied the Sema7A antibody staining technique to the analysis of cell death regulation in aged olfactory neurons in mice. Olfactory defects are common in human aging (Doty et al., 1984; Cain and Stevens, 1989). The adult OB retains the potential to regenerate new olfactory neurons, which counters the age-dependent olfactory defects (Kempermann et al., 2004). Although cell death plays an important role in regulating neurogenesis by eliminating old olfactory neurons in the $\mathrm{OB}$, the age-related changes in cell death and caspase signaling in these cells have remained unknown.

We therefore analyzed the $\mathrm{OB}$ in 2-month-old (young) and 2-year-old (aged) mice by Sema7A antibody staining (Fig. 5A-C). Sema7A-positive cells were observed in the granule cell layer (GCL) (Fig. 5C) and the glomerular layer (Fig. 5B) of the aged OB. However, only a few cells were immunolabeled with the anti-Sema7A antibody in the young $\mathrm{OB}$ (Fig. 5A). Although myelin loss and dam- age have been observed in the aged mouse brain (Bartzokis, 2004), the anti-Sema7A antibody failed to stain O4-positive oligodendrocytes. Immunoblotting confirmed the results of the staining analysis, revealing that Sema7A was cleaved in the aged OB (Fig. 5D).

We also measured caspase activity in young and aged neural tissues by using different caspase substrates, including AcYVAD-MCA (for caspase-1-like proteases), Ac-DEVD-MCA (caspase-3-like proteases), Ac-IETD-MCA (caspase-8-like proteases), and Ac-LEHD-MCA (caspase-9-like proteases). We found that the caspase-9-like LEHD-cleaving activity was dramatically increased in the aged brain, while the YVAD-, DEVD-, and IETD-cleaving activities had not changed, suggesting that caspase- 9 was specifically activated with aging (Fig. 6).

Intriguingly, no caspase-3 activation or caspase-3-dependent cleavage of PARP was observed in the aged $\mathrm{OB}$, even though these cells had increased caspase-9 activation (Fig. $6 B, D, 7 B$ ). Double staining of the $\mathrm{OB}$ for activated caspase- 3 and DNA fragmentation showed that the number of TUNEL-positive, active-caspase-3positive, and TUNEL-positive/active-caspase-3-positive cells decreased in the aged $\mathrm{OB}$, consistent with a previous report (Mirich et al., 2002) (Fig. 7A). We also found that the numbers of PSA-NCAMpositive immature neurons (Seki and Arai, 1991, 1993) were dramatically lower than in the young $\mathrm{OB}$, indicating that neurogenesis had also decreased in the aged OB (young OB: $62.9 \pm 8.85 \mathrm{cells} / \mathrm{mm}^{2}$ $\mathrm{OB}$; aged OB: $1.93 \pm 1.16$ cells $/ \mathrm{mm}^{2} \mathrm{OB}$; values are the mean \pm SEM; $n=3$; $t$ test; $p<0.01$ ) (Fig. $7 C$ ). These observations indicate that the activation of initiator caspase- 9 signaling is not always associated with downstream caspase- 3 activation in the aged brain. To keep olfactory cells alive in the aged $\mathrm{OB}$, which has reduced neurogenesis, a system for avoiding apoptotic cell death might be activated. To address the mechanism for this system, we examined the expression level of the procaspase-3 zymogen (Fig. 7B) and found that it was dramatically decreased in the aged OB. Together, these observations suggest that the downregulation of procaspase- 3 expression is a strategy used by aged $\mathrm{OB}$ neurons to survive under 


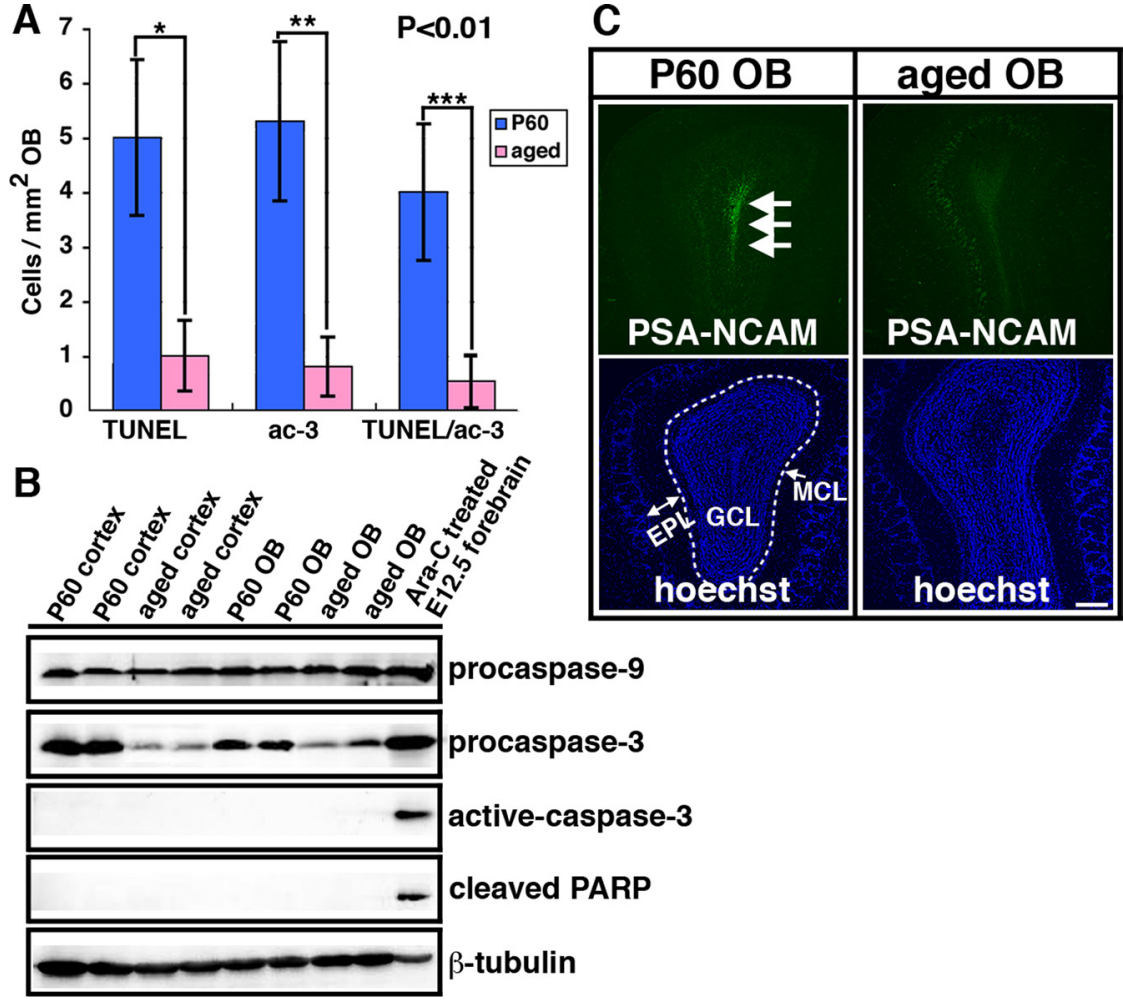

Figure 7. Decreased cell death, neurogenesis, and expression of procaspase-3 with age. $A$, Ten coronal sections ( $5 \mu \mathrm{m}$ thick) spaced at $100 \mu \mathrm{m}$ intervals in P60 and 24-month-old (aged) OB were subjected to the TUNEL assay, following immunofluorescence labeling with an anti-active-caspase-3 antibody. Labeled cells in the GCL, external plexiform layer (EPL), and mitral cell layer (MCL) were counted using fluorescence microscopy, and the total number of labeled cells is shown in the graph. Values are the mean \pm SEM $\left(n=3 ; t\right.$ test; $\left.{ }^{*} p<0.01\right)$. $\boldsymbol{B}$, Whole-cell extracts $(60 \mu \mathrm{g})$ of the indicated mouse tissues were analyzed by immunoblotting using anti-caspase- 9 , anti-caspase-3, anti-active-caspase-3, anti-cleaved PARP, and anti- $\beta$-tubulin antibodies. C, Ten coronal sections (5 $\mu \mathrm{m}$ thick) spaced at $100 \mu \mathrm{m}$ intervals in P60 and 24-month-old (aged) OB were immunolabeled. Immature neurons were detected with an anti-PSA-NCAM antibody. Labeled cells in the GCL were counted using fluorescence microscopy. Representative staining patterns with the anti-PSA-NCAM antibody (green) are shown for the indicated OE sections in C. Arrows show the PSA-NCAM-positive region in the young OB. Scale bar, $200 \mu \mathrm{m}$.

apoptotic conditions. Our results also suggest that high caspase- 9 activity performs a nonapoptotic function in the aged brain, partly through the modulation of axonal regulatory proteins, including Sema7A.

\section{Discussion}

An anti-Sema7A antibody specific for caspase-9-activated cells

The caspase-mediated cleavage of protein substrates is a hallmark of apoptosis. At present, $>400$ direct substrates of caspase- 3 have been identified (Lüthi and Martin, 2007). However, only a few proteins have been reported to be substrates for caspase- 9 , including vimentin and amyloid $\beta$-protein precursor (APP) (Lu et al., 2000; Nakanishi et al., 2001). Here we found that antiSema7A staining is a valuable method for the sensitive detection of caspase- 9 activity in tissue.

Why does this anti-Sema7A antibody recognize only the caspase9-cleaved form, thereby detecting caspase-9 activity? It is similar to the antibody against the active (cleaved) form of caspase-3, which immunostains dying cells. Intriguingly, the Sema7A antibody specifically stains caspase-9-activated cells, although it detects both the cleaved and uncleaved forms of Sema7A in immunoblots. We observed a similar phenomenon using an antibody that specifically immunolabels human brain abundant membrane-attached signal protein 1 (hBASP1) in caspase-activated dying cells (Ohsawa et al., 2008b). It is possible that these proteins undergo some sort of "apoptotic conformational changes" in cells, and the antibodies recognize these changes under immunostaining conditions. Since hBASP1 has been shown to relocate from the nucleus to the cytoplasm in apoptotic cells, the immunoreactivity of Sema7A might also depend on its subcellular localization.

Downregulation of procaspase- 3 is a strategy used by aged $\mathrm{OB}$ neurons to survive caspase- 9 activation

In this study, we found that caspase-9 activity was increased in the aged $\mathrm{OB}$, which was resistant to apoptotic cell death. It is difficult to distinguish whether Sema7Apositive filamentous structures are neurites or not. Given that there are no reliable markers for neurites in the $\mathrm{OB}$, because of the following observation, we preferred to consider that these Sema7Apositive filamentous structures are neurites. First, the anti-Sema7A antibody labeled neurites in Neuro 2a cells (Fig. $1 A, B)$. Second, the anti-Sema7A antibody labeled axons of the OSNs during late embryonic stage. This immunoreactivity to the OSN axons was not observed in the caspase-9- or apaf-1-deficient mice, suggesting that caspase-9-depedent cleaved Sema7A could localize in the neurites (S. Ohsawa and M. Miura, unpublished data). Together with the staining pattern that Sema7A-positive filamentous structures in the OB failed to immunolabel O4-positive oligodendrocytes, the antiSema7A antibody could label neurites of the olfactory neurons.

Nonapoptotic caspase-9 activation has been reported in the brain of Alzheimer's disease (AD) patients, where a fragment of APP cleaved at Asp-664 by caspase-9, APP-C31, is present (Lu et al., 2000). The role of APP-C31 in the pathogenesis of AD was examined in mice expressing APP with or without the Asp-664 caspase cleavage site (Galvan et al., 2006). Whereas $\beta$-amyloid production and plaque formation were unaffected, the synaptic loss, astrogliosis, and behavioral abnormalities characteristic of the $\mathrm{AD}$ phenotype were completely prevented by the Asp-664 mutation. These data suggest that the caspase-mediated processing of APP might trigger the onset of AD without immediately inducing cell death, since neurodegeneration occurs several months later. In addition, caspase- 9 activation is also observed in the spinal motor neurons of human ALS subjects, which contributes to the disease progression of a transgenic ALS mouse model (Inoue et al., 2003). Most neurodegenerative diseases, including $\mathrm{AD}$ and ALS, are characterized by the selective damaging of specific neuronal subsets that are not regenerated throughout life. Similarly, the $\mathrm{OB}$ virtually loses its ability to regenerate olfactory neurons in old age. Thus, the mechanism described here, of inhibiting apoptosis by reducing procaspase- 3 expression, might be essential for maintaining the overall cell number and homeostasis of olfactory neurons under aging and neurodegenerative conditions. 


\section{Evolution of cells' transition from sensitivity to resistance to apoptotic stimuli}

In aged mice, caspase- 9 activity failed to induce apoptotic cell death. Our data indicate that this interesting phenomenon was due to a significant reduction in the amount of the procaspase- 3 zymogen in the aged $\mathrm{OB}$, which might be insufficient to execute the cell death pathway. Interestingly, a similar idea was recently proposed in a study showing that epigenetic inactivation of the proapoptotic reaper and hid genes reduces the cell sensitivity to cytotoxic stimuli during Drosophila embryogenesis; proliferating cells in Drosophila embryos are highly sensitive to gamma-rayinduced apoptosis at early stages, but later become resistant to this stimulus in differentiating cells. Thus, the transition from sensitivity to resistance to apoptotic stimuli might have emerged in developmental processes and then been adopted by nervous systems in long-living animals through evolution.

\section{References}

Bartzokis G (2004) Age-related myelin breakdown: a developmental model of cognitive decline and Alzheimer's disease. Neurobiol Aging 25:5-18; author reply $49-62$.

Cain WS, Stevens JC (1989) Uniformity of olfactory loss in aging. Ann N Y Acad Sci 561:29-38.

Doty RL, Shaman P, Applebaum SL, Giberson R, Siksorski L, Rosenberg L (1984) Smell identification ability: changes with age. Science 226:1441-1443.

D'Sa C, Klocke BJ, Cecconi F, Lindsten T, Thompson CB, Korsmeyer SJ, Flavell RA, Roth KA (2003) Caspase regulation of genotoxin-induced neural precursor cell death. J Neurosci Res 74:435-445.

D'Sa-Eipper C, Leonard JR, Putcha G, Zheng TS, Flavell RA, Rakic P, Kuida K, Roth KA (2001) DNA damage-induced neural precursor cell apoptosis requires p53 and caspase 9 but neither Bax nor caspase 3. Development 128:137-146.

Fujita E, Egashira J, Urase K, Kuida K, Momoi T (2001) Caspase-9 processing by caspase-3 via a feedback amplification loop in vivo. Cell Death Differ 8:335-344.

Galvan V, Gorostiza OF, Banwait S, Ataie M, Logvinova AV, Sitaraman S, Carlson E, Sagi SA, Chevallier N, Jin K, Greenberg DA, Bredesen DE (2006) Reversal of Alzheimer's-like pathology and behavior in human APP transgenic mice by mutation of Asp664. Proc Natl Acad Sci U S A 103:7130-7135.

Inoue $\mathrm{H}$, Tsukita $\mathrm{K}$, Iwasato $\mathrm{T}$, Suzuki $\mathrm{Y}$, Tomioka $\mathrm{M}$, Tateno $\mathrm{M}$, Nagao $\mathrm{M}$, Kawata A, Saido TC, Miura M, Misawa H, Itohara S, Takahashi R (2003) The crucial role of caspase- 9 in the disease progression of a transgenic ALS mouse model. EMBO J 22:6665-6674.

Jacobson MD, Weil M, Raff MC (1997) Programmed cell death in animal development. Cell 88:347-354.

Kanuka H, Hisahara S, Sawamoto K, Shoji S, Okano H, Miura M (1999) Proapoptotic activity of Caenorhabditis elegans CED-4 protein in Drosophila: implicated mechanisms for caspase activation. Proc Natl Acad Sci U S A 96:145-150.

Kempermann G, Wiskott L, Gage FH (2004) Functional significance of adult neurogenesis. Curr Opin Neurobiol 14:186-191.

Koike M, Shibata M, Tadakoshi M, Gotoh K, Komatsu M, Waguri S, Kawahara N, Kuida K, Nagata S, Kominami E, Tanaka K, Uchiyama Y (2008) Inhibition of autophagy prevents hippocampal pyramidal neuron death after hypoxic-ischemic injury. Am J Pathol 172:454-469.

Kuida K, Zheng TS, Na S, Kuan C, Yang D, Karasuyama H, Rakic P, Flavell RA (1996) Decreased apoptosis in the brain and premature lethality in CPP32-deficient mice. Nature 384:368-372.

Kumar S (2004) Migrate, differentiate, proliferate, or die: pleiotropic functions of an apical "apoptotic caspase." Sci STKE 2004:pe49.

Kumar S (2007) Caspase function in programmed cell death. Cell Death Differ 14:32-43.

Kuo CT, Zhu S, Younger S, Jan LY, Jan YN (2006) Identification of E2/E3 ubiquitinating enzymes and caspase activity regulating Drosophila sensory neuron dendrite pruning. Neuron 51:283-290.

Kuranaga E, Miura M (2007) Nonapoptotic functions of caspases: caspases as regulatory molecules for immunity and cell-fate determination. Trends Cell Biol 17:135-144.

Kuranaga E, Kanuka H, Tonoki A, Takemoto K, Tomioka T, Kobayashi M, Hayashi S, Miura M (2006) Drosophila IKK-related kinase regulates nonapoptotic function of caspases via degradation of IAPs. Cell 126:583-596.
Lu DC, Rabizadeh S, Chandra S, Shayya RF, Ellerby LM, Ye X, Salvesen GS, Koo EH, Bredesen DE (2000) A second cytotoxic proteolytic peptide derived from amyloid beta-protein precursor. Nat Med 6:397-404.

Lüthi AU, Martin SJ (2007) The CASBAH: a searchable database of caspase substrates. Cell Death Differ 14:641-650.

Maruyama T, Matsuura M, Suzuki K, Yamamoto N (2008) Cooperative activity of multiple upper layer proteins for thalamocortical axon growth. Dev Neurobiol 68:317-331.

Mine T, Harada K, Matsumoto T, Yamana H, Shirouzu K, Itoh K, Yamada A (2000) CDw108 expression during T-cell development. Tissue Antigens 55:429-436.

Mirich JM, Williams NC, Berlau DJ, Brunjes PC (2002) Comparative study of aging in the mouse olfactory bulb. J Comp Neurol 454:361-372.

Miura M, Yuan J (1996) Mechanisms of programmed cell death in Caenorhabditis elegans and vertebrates. Curr Top Dev Biol 32:139-174.

Nakanishi K, Maruyama M, Shibata T, Morishima N (2001) Identification of a caspase- 9 substrate and detection of its cleavage in programmed cell death during mouse development. J Biol Chem 276:41237-41244.

Ohsawa S, Hamada S, Kakinuma Y, Yagi T, Miura M (2005) Novel function of neuronal PAS domain protein 1 in erythropoietin expression in neuronal cells. J Neurosci Res 79:451-458.

Ohsawa S, Hamada S, Yoshida H, Miura M (2008a) Caspase-mediated changes in histone $\mathrm{H} 1$ in early apoptosis: prolonged caspase activation in developing olfactory sensory neurons. Cell Death Differ 15:1429-1439.

Ohsawa S, Watanabe T, Katada T, Nishina H, Miura M (2008b) Novel antibody to human BASP1 labels apoptotic cells post-caspase activation. Biochem Biophys Res Commun 371:639-643.

Pasterkamp RJ, Peschon JJ, Spriggs MK, Kolodkin AL (2003) Semaphorin 7A promotes axon outgrowth through integrins and MAPKs. Nature 424:398-405.

Pasterkamp RJ, Kolk SM, Hellemons AJ, Kolodkin AL (2007) Expression patterns of semaphorin7A and plexinC1 during rat neural development suggest roles in axon guidance and neuronal migration. BMC Dev Biol 7:98.

Seki T, Arai Y (1991) Expression of highly polysialylated NCAM in the neocortex and piriform cortex of the developing and the adult rat. Anat Embryol (Berl) 184:395-401.

Seki T, Arai Y (1993) Highly polysialylated neural cell adhesion molecule (NCAM-H) is expressed by newly generated granule cells in the dentate gyrus of the adult rat. J Neurosci 13:2351-2358.

Slee EA, Harte MT, Kluck RM, Wolf BB, Casiano CA, Newmeyer DD, Wang HG, Reed JC, Nicholson DW, Alnemri ES, Green DR, Martin SJ (1999) Ordering the cytochrome c-initiated caspase cascade: hierarchical activation of caspases-2, $-3,-6,-7,-8$, and -10 in a caspase-9-dependent manner. J Cell Biol 144:281-292.

Srinivasula SM, Ahmad M, Fernandes-Alnemri T, Alnemri ES (1998) Autoactivation of procaspase- 9 by Apaf-1-mediated oligomerization. Mol Cell 1:949-957.

Srinivasula SM, Hegde R, Saleh A, Datta P, Shiozaki E, Chai J, Lee RA, Robbins PD, Fernandes-Alnemri T, Shi Y, Alnemri ES (2001) A conserved XIAPinteraction motif in caspase- 9 and Smac/DIABLO regulates caspase activity and apoptosis. Nature 410:112-116.

Suzuki K, Okuno T, Yamamoto M, Pasterkamp RJ, Takegahara N, Takamatsu H, Kitao T, Takagi J, Rennert PD, Kolodkin AL, Kumanogoh A, Kikutani H (2007) Semaphorin 7A initiates T-cell-mediated inflammatory responses through alphalbetal integrin. Nature 446:680-684.

Suzuki Y, Nakabayashi Y, Takahashi R (2001) Ubiquitin-protein ligase activity of X-linked inhibitor of apoptosis protein promotes proteasomal degradation of caspase- 3 and enhances its anti-apoptotic effect in Fasinduced cell death. Proc Natl Acad Sci U S A 98:8662-8667.

Takemoto K, Nagai T, Miyawaki A, Miura M (2003) Spatio-temporal activation of caspase revealed by indicator that is insensitive to environmental effects. J Cell Biol 160:235-243.

Thornberry NA, Rano TA, Peterson EP, Rasper DM, Timkey T, Garcia-Calvo M, Houtzager VM, Nordstrom PA, Roy S, Vaillancourt JP, Chapman KT, Nicholson DW (1997) A combinatorial approach defines specificities of members of the caspase family and granzyme B. Functional relationships established for key mediators of apoptosis. J Biol Chem 272:17907-17911.

Williams DW, Kondo S, Krzyzanowska A, Hiromi Y, Truman JW (2006) Local caspase activity directs engulfment of dendrites during pruning. Nat Neurosci 9:1234-1236.

Yoshida H, Kong YY, Yoshida R, Elia AJ, Hakem A, Hakem R, Penninger JM, Mak TW (1998) Apaf1 is required for mitochondrial pathways of apoptosis and brain development. Cell 94:739-750. 